\title{
A IMPORTÂNCIA DOS PROCESSOS MUSEOLÓGICOS PARA A PRESERVAÇÃO DO PATRIMÔNIO
}

\author{
Maria Cristina Oliveira Bruno*
}

\section{Apresentação}

A história dos museus tem sido permeada por valores relacionados à ostentação, à opulência e ao poder. Enquanto herdeiros institucionais das atitudes e procedimentos que têm amparado o colecionismo, os museus atravessaram os últimos séculos ampliando as suas perspectivas de atuação, organizando as suas plataformas técnico-científicas e, sobretudo, procurando definir a sua função social, por meio de distintos processos de extroversão.

É verdade que a construção da memória museológica tem evidenciado a sua cumplicidade com roubos e saques, colonialismo e depredação, entre tantos outros aspectos que colaboram para o delineamento de uma imagem difícil de ser assimilada e valorizada. Entretanto, a institucionalização deste tipo de tratamento da herança cultural tem contribuído para o desenvolvimento de diversas áreas científicas, para a conservação dos bens culturais, como também, para a educação através do patrimônio.

A partir de um olhar museológico é possível reconhecer que no Brasil, pelo menos há três décadas, inúmeras equipes de arqueólogos vêm realizando estudos sistemáticos com o objetivo de desvelar o nosso passado. ${ }^{1}$

Este processo, que tem envolvido as mais diferentes estruturas institucionais e interagido com distintas camadas da população, fez emergir uma avassaladora quantidade de vestígios que testemunham e documentam os horizontes culturais dos

(*) Museu de Arqueologia e Etnologia da Universidade de São Paulo.

(1) Alguns autores têm elaborado reflexões e análises críticas sobre a produção intelectual referente à Arqueologia no Brasil. Refiro-me, especialmente, a André Prous, Alfredo Mendonça de Souza e Pedro Paulo de Abreu Funari. grupos nativos que habitaram o território deste país. Por meio das mais diferenciadas intervenções, valendo-se de prospecções e escavações, ou de coleções já constituídas, é possível constatar que os estudos arqueológicos - responsáveis pela fidedignidade atribuída aos vestígios das sociedades que nos procederam - têm constituído um rico e multifacetado universo patrimonial. Desta forma, os arqueólogos têm assumido, também, maior visibilidade e compromissos sociais. ${ }^{2}$

Entretanto, muito dessa pesquisa ainda é imperceptível para aqueles que interpretam e constroem a história cultural brasileira e inatingível para a maioria da sociedade brasileira.

Esta comunicação expõe este problema, delimitado por fronteiras e barreiras de ordem museológica, considerando que, em grande parte a noção de patrimônio ${ }^{3}$ arqueológico depende dos museus, o que nos leva a considerar que os processos museológicos são essenciais para a preservação patrimonial.

Gostaria de sublinhar, preliminarmente, que esta abordagem procurou rastrear, em especial, o isolamento das instituições museológicas de Arqueologia e quais são os seus desafios contemporâneos.

A paisagem da nossa herança cultural musealizada - no que diz respeito aos vestígios das populações que antecederam a colonização - evidencia a necessidade de uma discussão a partir da consideração de quatro segmentados de problemas, a saber:

a) É necessário lembrar que a história das instituições museológicas, em geral, tem evi-

(2) Este tema é tratado de forma pormenorizada na tese "Musealização da Arqueologia: um estudo de modelos para o Projeto Paranapanema" (Bruno 1995).

(3) Entende-se por patrimônio o conjunto dos bens, fruto das relações entre os homens e os recursos naturais; entre os Homens em sociedade; e as interpretações que são elaboradas a partir destas relações. 
BRUNO, M.C.O. A importância dos processos museológicos para a preservação do Patrimônio. Rev. do Museu de Arqueologia e Etnologia, São Paulo, Suplemento 3: 333-337, 1999.

denciado uma reitorada cumplicidade com roubos, saques, espoliações, colonialismo e depredação e que os processos de musealização representam - muitas vezes - os olhares relacionados com o etnocentrismo exacerbado, com os vendedores e com o poder. Portanto, precisamos estar abertos às razões do esquecimento (exílio da memória) e encontrar os métodos adequados para cuidar da memória exilada.

b) Temos que reconhecer que a história da cultura brasileira tem sido construída sem prestar muita atenção nos indicadores culturais referentes às sociedades nativas. A literatura, a música, o teatro, o cinema raramente têm sido inspirados na vivência histórica précolonial. Nesta estratigrafia do abandono os museus têm uma grande responsabilidade, pois talvez representem a última camada, por não decodificarem com clareza os indicadores arqueológicos que estão sob sua guarda.

c) Não podemos negligenciar o fato de que a constituição de fenômenos museais e a implantação de processos museológicos dependem do respeito aos procedimentos de salvaguarda e comunicação dos artefatos, coleções e acervos, suas respectivas informações e contextualizações. Isto significa tratar da formação profissional e não desprezar a interdisciplinaridade. $^{+}$

d) Temos que inserir na pauta das discussões acadêmicas os temas vinculados aos modelos museológicos, à inserção das novas tecnologias, à devolução dos bens patrimoniais e à convivência inevitável entre imagem virtual e as coleções museológicas.

Esses quatro segmentos de problemas, na verdade, correspondem a duas questões básicas:

- qual é o perfil dos profissionais que moldam as instituições museológicas;

- quais são os paradigmas teórico-metodológicos que podem (ou poderiam) viabilizar a musealização da Arqueologia.

Assim, as minhas reflexões estão organizadas em duas partes, apresentadas a seguir.

(4) Entende-se por Museologia a disciplina que tem por objeto de estudo a relação entre o Homem e o Objeto cultural em um Cenário, por meio de procedimentos de salvaguarda e comunicação.

\section{Primeira Parte}

\section{Essa gente de museu e suas trincheiras:} algumas ponderações

A historiografia brasileira tem uma dívida para com os museus deste país. Raramente o fenômeno museal serviu de estímulo para os olhares decifradores dos profissionais desta área de estudos. Antropólogos e sociólogos, também, pouco têm orientado suas reflexões para o estudo das comunidades museológicas, seus impasses, características e suas trajetórias.

Os caminhos da convivência institucional que conduzem à construção da memória; as maneiras alternativas de como os profissionais brasileiros lançam mão da experiência museológica estrangeira; as razões subjacentes à organização de inúmeras coleções que preenchem os espaços dos museus por todo país; as formas de convivência com o assédio político, com a pressão dos meios de comunicação ou com os nossos próprios pares, entre muitos outros problemas, são apenas alguns aspectos inerentes a um universo infinitamente mais complexo. Somente nos últimos anos estas questões têm sido tratadas em poucos artigos e algumas teses.

Com temporalidade diferenciada, gerações de profissionais entram e saem do circuito museal brasileiro, conhecendo muito mais as experiências estrangeiras do que o eu próprio passado. $\mathrm{E}$ muitos nem se dão conta de que estão atuando em um cenário, com códigos secularmente estabelecidos e que conta com um lógica bem definida.

Estes profissionais, estes grupos, estas corporações, ou seja, nós mesmos, temos estudado e trabalhado para orientar, proteger e recriar a história patrimonial deste país, que tem mil faces, muitas memórias e uma identidade moldada na diversidade.

Administrar a memória ou, como alguns preferem, manipular as referências patrimoniais, a partir de objetos, coleções e acervos, pressupõe um Domínio seguro de métodos e técnicas de conservação da materialidade destas evidências culturais e da retenção documental dos significados destes indicadores da memória. Da mesma forma, gerenciar a coerência dos discursos expositivos pode representar uma grande possibilidade de intervenção na vida do público. E o que dizer da responsabilidade de educar, por meio dos museus, a partir dos objetos?

Essas características, com suas pequenas peculiaridades, representam a base das preocupações da Museologia - enquanto uma disciplina aplica- 
BRUNO, M.C.O. A importância dos processos museológicos para a preservação do Patrimônio. Rev. do Museu de Arqueologia e Etnologia, São Paulo, Suplemento 3: 333-337, 1999.

da - e ao mesmo tempo têm permitido aos museus a estruturação de limites (que para alguns são muralhas), permeados por idéias e mentalidades que direcionam as linhas de pesquisa e os temas das exposições; organizam as reservas técnicas do acervo; definem os códigos de identificação das coleções, entre tantas outras responsabilidades.

Esses limites têm permeado, sobretudo, as decisões que consagram ou desprezam certos valores culturais em detrimento de outros. Podemos identificar esse processo como medidor da apropriação e interpretação ativas do passado, e uma possibilidade real de retorno para a sociedade contemporânea que, por sua vez, procederá a novas apropriações e interpretações. E é desta forma que se consolida a noção de patrimônio arqueológico.

Entretanto, são raras as abordagens destas questões. Pode-se afirmar, inclusive, que são raras as avaliações públicas sobre as instituições museológicas. Poucas mantêm arquivos ou preservam os documentos da sua própria trajetória, o que as torna extremamente vulneráveis, por um lado ao ostracismo e, por outro, a qualquer tipo de intervenção.

É importante reconhecer que, ao mesmo tempo em que os brasileiros têm convivido com essas mentalidades museológicas, experimentaram, também, agudas mudanças que conduziram o país do Império à República, propiciaram a abolição da escravidão, as diásporas internas, a urbanização, o litígio sobre a terra, como também, desterramos sistematicamente os povos indígenas, não protegemos as florestas, as disputas regionais têm sido reiteradas, recebemos levas de imigrantes, entre muitas outras rupturas.

Ao longo deste mesmo período, o país tem procurado, de forma compulsiva, a sua identidade e convive com democracia episódica e ditadura reiterada.

A todos esses processos os museus estão relacionados, seja para abrigar a memória de seus fatos seja omitindo e esquecendo, pois estas instituições hierarquizam valores, super estimam as evidências culturais em relação às naturais e tratam a realidade patrimonial como verdade absoluta.

\section{Segunda Parte}

\section{Existe um futuro para o nosso passado? algumas propostas}

Compreender as idéias e mentalidades que têm sustentado os processos museológicos inerentes à
Arqueologia Brasileira, para discutir a sua importância, significa aceitar o seu papel de coadjuvante.

Para tanto, deve ser destacado que o Brasil surgiu no cenário museológico internacional no século XIX, durante o período áureo destas instituições, em um momento de grande impulso das Ciências Naturais. Neste período, a Arqueologia Pré-histórica dava os seus primeiros passos, quando os ricos países, com industrialização emergente e imbuídos de uma ética expansionista, organizavam grandes expedições científicas, envolvendo este país em suas empreitadas neocolonializadoras.

Estes olhares estrangeiros, à frente dos primeiros museus, salvo alguns momentos episódicos, não valorizaram os vestígios arqueológicos. A partir deste momento teve início o longo caminho de coadjuvante da Arqueologia musealizada no Brasil.

Após a criação do Museu Nacional (1818 no Rio de Janeiro), outras instituições surgiram nos grandes centros brasileiros, à semelhança dos modelos internacionais e como resultado do desenvolvimento econômico localizado. Nestes museus, durante muito tempo, a Arqueologia foi coadjuvante das Ciências Naturais e da Etnologia.

Cabe mencionar que, desde o início estas instituições têm sido rivais e raramente têm atuado de forma integrada. Este "modelo fundador" do conceito de museu científico vai influenciar o surgimento de instituições congêneres nas principais cidades.

As décadas dos anos trinta e quarenta deste século, que assistiram as grandes discussões preservacionistas e, quando pela primeira vez no país foi elaborado um plano museológico, referente à implantação de Museus Nacionais, culminam com a criação de inúmeros museus vocacionados à preservação da memória colonial. Estes museus que evocavam, por exemplo, a Inconfidência, o Império, a Arte Sacra Católica, abandonaram totalmente a contribuição das sociedades nativas. Refiro-me, também, ao Museu Histórico Nacional, aberto em 1932 que não contemplou as referências patrimoniais pré-coloniais.

A criação do Instituto de Patrimônio Histórico e Artístico Nacional - IPHAN, em 1937, não atendeu, também, às necessidades do patrimônio arqueológico. Este problema só começou a ser superado na década de sessenta, com uma legislação específica elaborada por Paulo Duarte.

Ao mesmo tempo, nessas décadas e nas seguintes, muitos exploradores e amadores percorreram, incessantemente, diversas regiões do país 
BRUNO, M.C.O. A importância dos processos museológicos para a preservação do Patrimônio. Rev. do Museu de Arqueologia e Etnologia, São Paulo, Suplemento 3: 333-337, 1999.

e, a partir de distintos critérios, passaram a constituir as suas coleções particulares que, via de regra, deram origem a pequenos e isolados museus, descontextualizados de uma política nacional para a cultura ou mesmo regional.

A partir da década de sessenta, surgiram grandes projetos de levantamento e pesquisa no âmbito da Arqueologia, estilhaçando o território nacional e aumentando de forma considerável a quantidade de vestígios nos museus.

Esta forma muito particular da Arqueologia de produzir conhecimento no Brasil, transformou algumas instituições em verdadeiros guetos. $\mathrm{O}$ diálogo e a troca de experiências são conquistas recentes. Mesmo a configuração universitária que passou a ser representativa, a partir da década de setenta, pouco contribuiu para as aproximações entre as equipes, as análises e as relações sobre dados patrimoniais.

Portanto, se as estruturas básicas legaram à musealização da Arqueologia um papel de coadjuvante, o seu desenvolvimento científico foi acompanhado por grandes disputas e isolamento. Muitas universidades optaram por outros modelos institucionais para a produção de conhecimento arqueológico. São comuns, nas últimas décadas, a criação de núcleos, departamentos e institutos, isolando ainda mais as instituições museológicas. Ao longo deste período outros tipos de museus assumiram papéis de destaque no cenário patrimonial, como os de Arte Moderna, Cultura Popular, Ciências, sem contar os impactos dos Centros Culturais.

É possível afirmar que a partir dos anos oitenta o país já contava com equipes estáveis e bem preparadas, em diversas regiões, e também com um diálogo permeado pela Sociedade de Arqueologia Brasileira - SAB, Instituto de Patrimônio Histórico e Artístico Nacional e Cursos de Formação Profissional. Entretanto, a questão patrimonial ainda não foi privilegiada.

Recentemente, este caminho foi mais uma vez cortado pelos impactos da Arqueologia de Salvaguarda (ou Arqueologia de Contrato, como alguns identificam), que cobre o país todo e envolve quase todos os profissionais e instituições.

A partir deste breve histórico é possível afirmar que apenas algumas instituições entendem que estão comprometidas com as questões patrimoniais, além do desenvolvimento de projetos de pesquisa. Neste processo - quase esquisofrênico -, a Arqueologia musealizada no Brasil sublimou algumas importantes conquistas ocorridas em diver- sas partes do mundo. Refiro-me, especialmente, aos seguintes aspectos:

- a musealização vocacionada para as questões da identidade;

- a necessária aproximação ente os museus "arqueológico-artísticos" e os "arqueológicos-tecnológicos";

- as discussões sobre as opções entre "reservas técnicas" e os "depósitos de pesquisa" para a guarda dos acervos;

- a elaboração de exposições argumentativas;

- a utilização da Arqueologia Experimental para a implantação de projetos educativos;

- a abordagem dos conceitos de patrimônio integral, ecomuseu ou museu de território.

Neste horizonte de difícil assimilação, conseguimos perceber que algumas instituições estão reagindo, passando por avaliações e planejamentos estratégicos. Entretanto, em geral, este cenário é desolador e é possível identificar três síndromes, as saber:

\section{$l^{a}$ Síndrome: mito da origem}

Desde o início, a Arqueologia não foi bem equacionada nos museus, perdeu espaço para outras áreas e raramente conseguiu superar os problemas de salvaguarda e comunicação, ou seja:

- dominar a informação referente à avassaladora quantidade de vestígios.

- elaborar sínteses que pudessem ser compreendidas pelos leigos.

\section{$2^{a}$ Síndrome: mito do conceito}

Ainda não conseguimos elaborar, com clareza, o conceito do "Museu do Homem Americano". Entre as idéias de Paulo Duarte, à realidade de São Raimundo Nonato, encontram-se todas as nossas dúvidas sobre como enquadrar a Arqueologia do ponto de vista local, regional, nacional e universal.

\section{$3^{a}$ Síndrome: mito do futuro}

Para um olhar museológico, a Arqueologia de Salvamento / Contrato é uma questão 
BRUNO, M.C.O. A importância dos processos museológicos para a preservação do Patrimônio. Rev. do Museu de Arqueologia e Etnologia, São Paulo, Suplemento 3: 333-337, 1999.

extremamente difícil de ser assimilada, no que se refere a enorme quantidade de vestígios que tem sido coletados e armazenados nos museus. Os processos museológicos poderiam ser relevantes para a Arqueologia, se conseguíssemos superar estas três síndromes. Para tanto, precisamos avaliar as grandes instituições a partir de um diagnóstico e da elaboração de um plano diretor, que assegure o gerenciamento da informação e a comunicação museológica, além da produção de conhecimento. É importante, também, resgatar a Arqueologia perdida nas pequenas instituições e nas cole- ções particulares, considerando que todos estes esforços estão relacionados com o conceito de Museu do Homem Americano. Cabe registrar, ainda, que uma alternativa para minimizar os impactos da Arqueologia de Salvaguarda poderia ser a perspectiva aberta pela musealização dos territórios.

Finalmente, para responder à pergunta se existe um futuro para o nosso passado, é possível responder afirmativamente, mas a nossa ação é fundamental neste processo e a Museologia pode colaborar no que tange à salvaguarda e comunicação dos vestígios arqueológicos.

\section{Referências bibliográficas}

\section{BRUNO, M.C.O \\ 1995 Musealização da Arqueologia: um estudo de modelos para o projeto Paranapanema. São Pau- lo: FFLCH/USP, Tese de doutoramento.}

PROUS, A.

1991 Arqueologia Brasileira. Brasília: Universidade de Brasília.
FUNARI, P.P.A.

1994 Arqueologia Brasileira - visão geral e reavaliação. Revista de História da Arte e Arqueologia, Campinas, 1.

SOUZA, A.M.

1991 História da Arqueologia Brasileira. Pesquisas. Antropologia, São Leopoldo, 46. 